\title{
Learning complex cell units from simulated prenatal retinal waves with slow feature analysis Sven Dähne*1, Niko Wilbert ${ }^{1,2}$ and Laurenz Wiskott ${ }^{1,2}$
}

\author{
Address: ${ }^{1}$ Bernstein Center for Computational Neuroscience, Humboldt Universität zu Berlin, 10099 Berlin, Germany and ${ }^{2}$ Institute for \\ Theoretical Biology, Humboldt Universität zu Berlin, 10115 Berlin, Germany \\ Email: Sven Dähne* - sven.daehne@bccn-berlin.de \\ * Corresponding author
}

from Eighteenth Annual Computational Neuroscience Meeting: CNS*2009

Berlin, Germany. 18-23 July 2009

Published: 13 July 2009

BMC Neuroscience 2009, I0(SuppI I):PI 29 doi:I0.II86/I47I-2202-I0-SI-PI29

This abstract is available from: http://www.biomedcentral.com//47I-2202/I0/SI/PI29

(c) 2009 Dähne et al; licensee BioMed Central Ltd.

Many properties of the developing visual system are structured and organized before the onset of vision. Spontaneous neural activity, which spreads in waves across the retina, has been suggested to play a major role in these prenatal structuring processes [1]. Recently, it has been shown that when employing an efficient coding strategy, such as sparse coding, these retinal activity patterns lead to basis functions that resemble optimal stimuli of simple cells in V1 [2].

Here we present the results of applying a coding strategy that optimizes for temporal slowness, namely Slow Feature Analysis (SFA) [3], to a biologically plausible model of retinal waves [4] (see figure 1). We also tested other wave-like inputs (sinusoidal waves, moving Gauss blobs) that allow for an analytical understanding of the results. Previously, SFA has been successfully applied in modeling parts of the visual system, most notably in reproducing a rich set of complex cell features by training SFA with natural image sequences [5]. In this work, we were able to obtain complex-cell like receptive fields in all input conditions, as displayed in figure 2 .

Our results support the idea that retinal waves share relevant temporal and spatial properties with natural images. Hence, retinal waves seem suitable training stimuli to learn invariances and thereby shape the developing early visual system so that it is best prepared for coding input from the natural world.

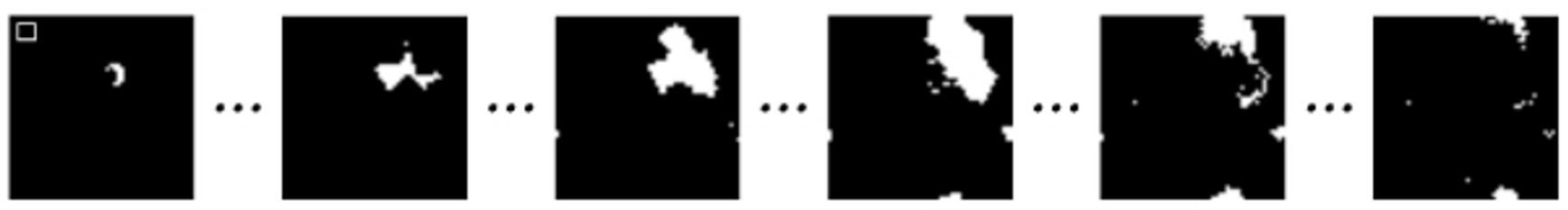

\section{Figure I}

Retinal wave training sequence. Snapshots of an image sequence that was generated by the retinal wave model described in [I] and used as input to SFA. A white square in the top left corner of the first image indicates the receptive field size. 
a
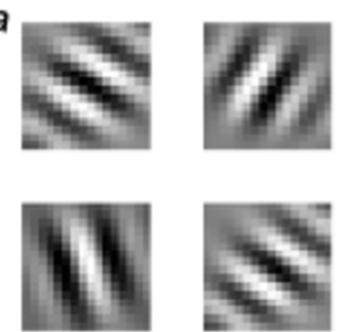

$b$

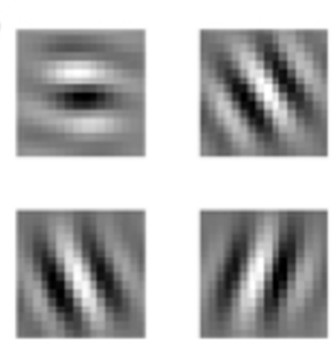

$c$
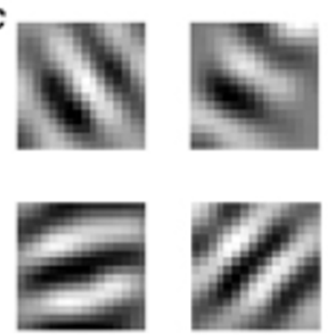

$d$
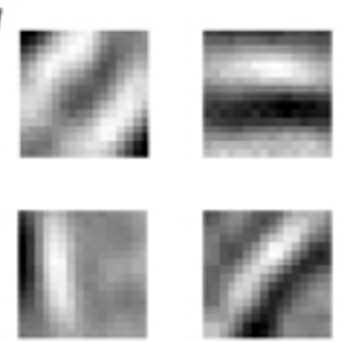

Figure 2

A sample of optimal stimuli of quadratic functions found by SFA, after training with different inputs. Training sequences derived from natural images and pink noise images result in optimal stimuli ( $A$ and $B$, respectively) that exhibit complex cell properties as expected (compare [2]). Training with discretized moving Gaussian blobs and the retinal wave model results in optimal stimuli ( $C$ and $D$, respectively) that are similar to those in $(A)$ and (B). All units show phase invariance similar to complex cells.

\section{References}

I. Wong ROL: Retinal waves and visual system development. Annu. Rev. Neurosci 1999, 22:28-47.

2. Albert MV, Schnabel A, Field DJ: Innate visual learning through spontaneous activity patterns. PLoS Comput Biol 2008, 4:.

3. Wiskott L, Sejnowski TJ: Slow feature analysis: unsupervised learning of invariances. Neural Computation 2002, 14:715-770.

4. Godfrey KB, Swindale NV: Retinal wave behavior through activity-dependent refractory periods. PLoS Comput Biol 2007, 3:2408-2420.

5. Berkes $P$, Wiskott $L$ : Slow feature analysis yields a rich repertoire of complex cell properties. J. Vision 2005, 5:579-602.

Publish with Bio Med Central and every scientist can read your work free of charge

"BioMed Central will be the most significant development for disseminating the results of biomedical research in our lifetime. "

Sir Paul Nurse, Cancer Research UK

Your research papers will be:

- available free of charge to the entire biomedical community

- peer reviewed and published immediately upon acceptance

- cited in PubMed and archived on PubMed Central

- yours - you keep the copyright
BioMedcentral 